\title{
LA MIGRACIÓN EN ARGENTINA, ASPECTOS GENERALES E HISTÓRICOS
}

\author{
Eusebio Francisco Tulio Flores Contreras, ${ }^{1}$ \\ Tarsila González Camacho, Eusebio F. Flores Barraza ${ }^{2}$
}

Sumario: I. Breve reseña histórica; II. Actual marco legal y políticas migratorias de Argentina; III. Organismos de protección de Derechos Humanos relacionados con la migración, en Argentina; IV.El caso de Juan Carlos De la Torre; V. Conclusiones; VI. Referencias-Bibliografía

Resumen.- El presente trabajo aborda las temáticas históricas que permiten comprender la importancia que tuvo y tiene actualmente la migración en la República Argentina. Asimismo las normativas jurídicas en materia migratoria, así como el estudio de caso del C. Juan Carlos de la Torre, migrante uruguayo a quien le fueron violados sus derechos humanos por parte de la autoridad migratoria. En este trabajo se pretende mostrar de forma general la situación de la migración en Argentina. Mostrar de qué manera fueron cambiando sus políticas migratorias, así como señalar algunas de las instituciones de asistencia jurídica que tienen los migrantes en éste país.

Palabras clave.- Migración, Instituciones de Asistencia Jurídica y Derechos Humanos de los migrantes extranjeros.

Abstract. - The present essay was realized during the exchange of the student scholar at the city of Buenos Aires. That's why, we're going to explore historic facts that will help us to understand the importance of the migration in Argentina. Also, we will be talking about legal norms on migration issues, and the case "Juan Carlos de la Torre", Uruguayan migrant that suffered violations in his human rights by the migration authority. This essay is intended to demonstrate in a general way the situation of the migration in Argentina. Show how the migration policies were changing, and point out the Legal Aid Institutes that migrant people have in this country.

Key words. Migration, Legal Aid Institutes and Human Rights of the foreign migrants.

Résumé.- Le présent travail a été créé pendant l'échange du boursier à Buenos Aires. C'est pourquoi nous allons explorer des événements historiques qui nous

1 Alumno becario, Ayudante de investigación de la Academia de Derecho Internacional de la Universidad de Sonora

${ }^{2}$ Docentes Investigadores Tiempo Completo adscritos al DD,DCS,URC,UNISON

${ }^{2}$ Docentes Investigadores Tiempo Completo adscritos al DD,DCS,URC,UNISON 
permettront comprendre l'importance de la migration en Argentine, Apres, nous allons parler sur normes juridiques en matière migratoire, et de la même manière, nous allons analyser l'affaire judiciaire "Juan Carlos de la Torre " migrant uruguayen dont ses droits fondamentaux ont été violés par l'Autorité Migratoire.

Ce travail vise à montrer d'une manière générale la situation de la migration en Argentine. Montrer comme les politiques migratoires ont changé et les Institutions d'Assistance Juridique qui aident aux migrants étrangers en Argentine.

Mots clés.- Migration, Institutions pour l'Assistance Juridique et Droits Fondamentaux des migrants étrangers.

\section{Breve reseña histórica}

Durante finales del siglo XIX y la primera mitad del siglo XX, Argentina pasó por un periodo histórico denominado por muchos "la Gran Inmigración", lo que generó en gran parte la actual composición étnica de este país.

La migración hacia la República Argentina durante el siglo XIX y principios del siglo XX se caracterizó por ser de ultramar y en su mayoría proveniente de Europa, transformándose así en el segundo país receptor de inmigrantes europeos después de Estados Unidos.

La inmigración de ultramar fue esencial en el poblamiento del país, aportando entre 1881-1914 con alrededor de 4 millones 200 mil individuos. Las corrientes más numerosas se manifestaron antes de la Primera Guerra Mundial, y en el año 1914 el número de inmigrantes alcanzó su máximo nivel histórico en términos relativos, con un impacto del $30 \%$ en el total de la población. ${ }^{3}$

Y es que para mediados del siglo XIX, Argentina adopta una política de aceptación o atracción a inmigrantes, con la idea de que en su mayoría fueran inmigrantes provenientes de Europa. Tal política la podemos encontrar en sus rasgos más generales en la Constitución de la Nación Argentina, en su artículo 25:

El Gobierno federal fomentará la inmigración europea; y no podrá restringir, limitar ni gravar con impuesto alguno la entrada en el territorio argentino de los extranjeros que traigan por objeto labrar la tierra, mejorar las industrias, e introducir y enseñar las ciencias y las artes.

${ }^{3}$ Sistema Continuo de Reportes sobre Migración Internacional en las Américas SICREMI, Argentina - Síntesis histórica de la migración internacional en Argentina, 2014 [en línea] Disponible: http://www.migracionoea.org/index.php/es/sicremies/17-sicremi/publicacion-2011/paises-es/53-argentina-1-sintesis-historica-de-lamigracion-internacional-en-argentina.html 
Sin embargo, este dispositivo se encuentra fuera de contexto, pues como veremos más adelante, las políticas migratorias han ido cambiando, máxime que actualmente existe el porcentaje de inmigraciones que ya no provienen solamente de Europa sino de países limítrofes.

De acuerdo al Censo de Población del año 1991, los inmigrantes limítrofes ya representaban más del cincuenta por ciento del total de la población extranjera. En el siguiente censo que fue realizado en el año 2001, la población limítrofe y peruana representaba dos tercios del total de los extranjeros, llegando en el censo del 2010 a superar el setenta y cinco por ciento.

Este predominio de la población migrante limítrofe en Argentina es el resultado de una tendencia, registrada desde hace varias décadas, a raíz de los cambios de las dos corrientes migratorias más importantes en la Argentina (la proveniente de los países europeos y la de los limítrofes), que determina una transformación en la composición de la población extranjera. Por un lado los migrantes europeos pierden peso progresivamente, debido a la alta tasa de mortalidad por el envejecimiento y el cese de los flujos migratorios provenientes de dicho continente, en tanto que la inmigración limitrofe ha mantenido un crecimiento en términos absolutos en todo el periodo. $^{4}$

\section{Actual marco legal y políticas migratorias de Argentina.}

La Constitución Nacional de la República Argentina otorga derechos civiles y sociales a todos sus habitantes, argentinos y extranjeros. Define la condición civil del extranjero a través de los artículos 14 y 20: el primero, general para todos los habitantes de la Nación; el segundo, especial para los extranjeros. En esta norma se suscribe que a los extranjeros debe asegurárseles el goce de los derechos de propiedad, trabajo, comercio e industria, locomoción, petición, publicidad, asociación, culto, enseñanza, conforme a las leyes reglamentarias. ${ }^{5}$

Lo anterior lo podemos complementar con la reforma constitucional de 1994, en la cual los tratados y convenios internacionales se elevan a rango constitucional ${ }^{6}$.

${ }^{4}$ Organización Internacional para las migraciones (OIM), El Impacto de las Migraciones en Argentina, Cuadernos migratorios No. 2. Abril 2012, pp. 18-19 ${ }^{5}$ Organización Internacional para las migraciones (OIM), Perfil Migratorio de Argentina 2012. P. 71.

${ }^{6}$ Reforma que no se haría en México sino hasta mayo de 2011. 
Quedando así contemplado en el artículo 75, inciso 22 de la Constitución Argentina:

"Le corresponde al Congreso...Aprobar o desechar tratados concluidos con las demás naciones y con las organizaciones internacionales y los concordatos con la Santa Sede. Los tratados y concordatos tienen jerarquía superior a las leyes. La Declaración Americana de los Derechos y Deberes del Hombre; la Declaración Universal de Derechos Humanos; la Convención Americana sobre Derechos Humanos; el Pacto Internacional de Derechos Económicos, Sociales y Culturales; el Pacto Internacional de Derechos Civiles y Políticos y su Protocolo Facultativo; la Convención Sobre la Prevención y la Sanción del Delito de Genocidio; la Convención Internacional sobre la Eliminación de Todas las Formas de Discriminación Racial; la Convención Sobre la Eliminación de Todas las Formas de Discriminación Contra la Mujer; la Convención Contra la Tortura y Otros Tratos o Penas Crueles, Inhumanos o Degradantes; la Convención Sobre los Derechos del Niño; en las condiciones de su vigencia, tienen jerarquía constitucional, no derogan artículo alguno de la primera parte de esta Constitución y deben entenderse complementarios de los derechos y garantías por ella reconocidos. Solo podrán ser denunciados, en su caso, por el Poder Ejecutivo Nacional, previa aprobación de las dos terceras partes de la totalidad de los miembros de cada Cámara. Los demás tratados y convenciones sobre derechos humanos, luego de ser aprobados por el Congreso, requerirán el voto de las dos terceras partes de la totalidad de los miembros de cada Cámara para gozar de la jerarquía constitucional."

En 2003, tras varios años de activismo coordinado, el Congreso argentino aprobó por unanimidad una nueva Ley de Migraciones, la primera en la región en reconocer el derecho humano a migrar. La ley subrayó la obligación del Estado de facilitar la regularización (lo cual permitió a casi 1 millón de personas obtener su documentación entre 2004 y 2014), garantizó el debido proceso cuando los migrantes se enfrentaban a la deportación y limitó fuertemente el recurso de la detención. Este nuevo marco legal tuvo tal impacto en la región que inspiró reformas en otros países: Uruguay, Bolivia, Ecuador, Perú y, finalmente, Brasil. ${ }^{7}$ La Ley de Migraciones de Argentina, establece una nueva política migratoria por medio de la cual se fijan líneas de acción acordes con los compromisos internacionales de Argentina en materia de derechos humanos e integración

${ }^{7}$ CELS Estudio de caso Derechos de las personas migrantes: Compartir y ampliar las lecciones aprendidas en la Argentina, Mayo 2007, pp. 2-3, [En línea] Disponible: https://www.cels.org.ar/web/wp-content/uploads/2017/06/Estudio-decaso-del-CELS-sobre-derechos-de-los-migrantes.pdf 
económica. Además de garantizar el respeto de los derechos humanos de los migrantes, esta ley establece los derechos y obligaciones de extranjeros, su admisión y permanencia, así como algunas disposiciones sobre los nacionales en el exterior.

Esta misma establece que la admisión de extranjeros para ingresar y permanecer en el país se lleva a cabo en las categorías de "residentes permanentes", "residentes temporarios", o "residentes transitorios". Con excepciones, la autoridad de aplicación podrá conceder una autorización de "residencia precaria", que será revocable por la misma, si se desnaturalizan los motivos que se tuvieron en cuenta para su otorgamiento.

Se podrá autorizar la entrada al país de los extranjeros que no reúnan los requisitos establecidos en la ley y su reglamentación, cuando existan razones excepcionales de índole humanitaria, interés público o cumplimiento de compromisos adquiridos por Argentina.

Para poder adentrarnos en las clasificaciones de residencia debemos analizar diversos artículos de la citada Ley de Migraciones.

El artículo 22 dice que:

Se considerará "residente permanente" a todo extranjero que, con el propósito de establecerse definitivamente en el país, obtenga de la Dirección Nacional de Migraciones una admisión en tal carácter. Asimismo, se considerarán residentes permanentes los inmigrantes parientes de ciudadanos argentinos, nativos o por opción, entendiéndose como tales al cónyuge, hijos y padres. A los hijos de argentinos nativos o por opción que nacieren en el extranjero se les reconoce la condición de residentes permanentes. Las autoridades permitirán su libre ingreso y permanencia en el territorio.

Por otro lado, el artículo 23 nos dice que:

Se considerarán "residentes temporarios" todos aquellos extranjeros que, bajo las condiciones que establezca la reglamentación, ingresen al país en las siguientes subcategorías: a) Trabajador migrante: quien ingrese al país para dedicarse al ejercicio de alguna actividad lícita, remunerada, con autorización para permanecer en el país por un máximo de tres (3) años, prorrogables, con entradas y salidas múltiples, con permiso para trabajar bajo relación de dependencia; b) Rentista:

Quien solvente su estadía en el país con recursos propios traídos desde el exterior, de las rentas que estos produzcan o de cualquier otro ingreso lícito proveniente de fuentes externas. Podrá concederse un término de residencia de hasta tres (3) 20 años, prorrogables, con entradas y salidas múltiples; c) Pensionado: quien perciba de un 
gobierno o de organismos internacionales o de empresas particulares por servicios prestados en el exterior, una pensión cuyo monto le permita un ingreso pecuniario regular y permanente en el país; Podrá concederse un término de residencia de hasta tres (3) años, prorrogables, con entradas y salidas múltiples; d) Inversionista: quien aporte sus propios bienes para realizar actividades de interés para el país. Podrá concederse un término de residencia de hasta tres (3) años, prorrogables, con entradas y salidas múltiples; e) Científicos y personal especializado: quienes se dediquen a actividades científicas, de investigación, técnicas, o de asesoría, contratados por entidades públicas o privadas para efectuar trabajos de su especialidad. De igual forma, directivos, técnicos y personal administrativo de entidades públicas o privadas extranjeras de carácter comercial o industrial, trasladados desde el exterior para cubrir cargos especificos en sus empresas y que devengue honorarios o salarios en la República Argentina. Podrá concederse un término de residencia de hasta tres (3) años, prorrogables, con entradas y salidas múltiples; f) Deportistas y artistas: contratados en razón de su especialidad por personas físicas o jurídicas que desarrollan actividades en el país. Podrá concederse un término de residencia de hasta tres (3) años, prorrogables, con entradas y salidas múltiples; g) Religiosos de cultos reconocidos oficialmente, con personería jurídica expedida por el Ministerio de Relaciones Exteriores, Comercio Exterior y Culto, que ingresen al país para desarrollar en forma exclusiva actividades propias de su culto. Podrá concederse un término de residencia de hasta tres (3) años, prorrogables, con entradas y salidas múltiples; h) Pacientes bajo tratamientos médicos: para atender problemas de salud en establecimientos sanitarios públicos o privados, con autorización para permanecer en el país por un año, prorrogable, con entradas y salidas múltiples. En caso de personas menores 21 Ley Migraciones 25.871 de edad, discapacitados o enfermos que por la importancia de su patología debieran permanecer con acompañantes, esta autorización se hará extensiva a los familiares directos, representante legal o curador; i) Académicos: para quienes ingresen al país en virtud de acuerdos académicos celebrados entre instituciones de educación superior en áreas especializadas, bajo la responsabilidad del centro superior contratante. Su vigencia será por el término de hasta un (1) año, prorrogable por idéntico período cada uno, con autorización de entradas y salidas múltiples; j) Estudiantes:

Quienes ingresen al país para cursar estudios secundarios, terciarios, universitarios o especializados reconocidos, como alumnos regulares en establecimientos educativos públicos o privados reconocidos oficialmente, con autorización para permanecer en el país por dos (2) años, prorrogables, con entradas y salidas múltiples. El interesado deberá demostrar la inscripción en la institución educativa en la que 
cursará sus estudios y, para las sucesivas renovaciones, certificación de su condición de estudiante regular; k) Asilados y refugiados: Aquellos que fueren reconocidos como refugiados o asilados se les concederá autorización para residir en el país por el término de dos (2) años, prorrogables cuantas veces la autoridad de aplicación en materia de asilo y refugio lo estime necesario, atendiendo a las circunstancias que determine la legislación vigente en la materia; I) Nacionalidad: Ciudadanos nativos de Estados Parte del MERCOSUR, Chile y Bolivia, con autorización para permanecer en el país por dos (2) años, prorrogables con entradas y salidas múltiples; $m$ ) Razones Humanitarias: Extranjeros que invoquen razones humanitarias que justifiquen a juicio de la Dirección Nacional de Migraciones un tratamiento especial; n) Especiales: Quienes ingresen al país por razones no contempladas en los incisos anteriores y que sean consideradas de interés por el Ministerio del Interior y el Ministerio de Relaciones Exteriores, Comercio Internacional y Culto.

Sin embargo, en enero de 2017 el gobierno argentino emitió un Decreto de Necesidad y Urgencia (DNU) que desarmó algunas disposiciones clave de la Ley de Migraciones: permitió la expulsión de personas por infracciones relacionadas con la migración y delitos menores, y creó un procedimiento sumario de deportación que viola el debido proceso, el derecho a la defensa y el acceso a la justicia. $^{8}$

Para fundamentar tal reforma, el Estado Argentino sostiene que para garantizar el objetivo de sus políticas migratorias y la potestad que tiene como nación de establecer normas y reglas para la entrada y salida o permanencia de personas en territorio argentino, era necesario mirar hacia lo tardado que podía ser los procesos administrativos y judiciales en materia migratoria, que podían derivar en una violación al debido proceso y acarrear una responsabilidad para el Estado Argentino.

A su vez, este proceso migratorio especial de carácter sumario, que de forma general es aplicable para personas que se encuentren implicadas en algún proceso penal, o que entren de forma clandestina a territorio argentino, genera mucha polémica ya que los principios del debido proceso y acceso a la justicia de los inmigrantes se ven vulnerados en virtud de la supuesta celeridad y eficacia que busca obtener el Estado Argentino.

${ }^{8}$ Centro de Estudios Legales y Sociales (CELS), "El trabajo del CELS. Derechos de las personas migrantes: compartir y ampliar lecciones aprendidas en la Argentina." Mayo 2017. P. 4 
Y es que esta esta nueva política se presenta como una forma de estigmatizar a los inmigrantes, ya que la gente empieza a asociar a éstos con sectores como el narcotráfico, contrabando, crimen organizado, etc., cuando en realidad no es así.

\section{Organismos de protección de Derechos Humanos relacionados con la migración, en Argentina.}

Dentro de esta categoría podemos hablar de dos clases de organismos, las Instituciones Nacionales de Derechos Humanos (INDH) y los Organismos No Gubernamentales (ONG).

Instituciones Nacionales de Derechos Humanos (INDH)

Por INDH se entiende un órgano establecido por un gobierno en virtud de la constitución o por la ley, cuyas funciones principales son la promoción y protección de los derechos humanos.

Aunque son organismos que derivan del Estado, estos no pertenecen ni al poder Ejecutivo, Legislativo o Judicial, sino por el contrario, se tratan de organismos autónomos, con patrimonio y personalidad jurídica propia. ${ }^{9}$

Defensor del Pueblo de la Nación-Ombudsman Nacional.

Este organismo es un ejemplo claro de una INDH. Éste se instauró a través de la Ley No. 24.284 de creación del Defensor del Pueblo por los años noventa. La misma ley nos dice en su artículo 14 la competencia que tiene el Defensor del Pueblo:

“...El Defensor del Pueblo puede iniciar y proseguir de oficio o a petición del interesado cualquier investigación conducente al esclarecimiento de los actos, hechos u omisiones de la administración pública nacional y sus agentes, que impliquen el ejercicio ilegítimo, defectuoso, irregular, abusivo, arbitrario, discriminatorio, negligente, gravemente inconveniente o inoportuno de sus funciones, incluyendo aquellos capaces de afectar los intereses difusos o colectivos..."

La Resolución DPA N 037/2005 que establece la estructura organizativa del Defensor del Pueblo fija entre las competencias del Área de Derechos Humanos analizar, investigar y proponer los cursos de acción en materia de migraciones,

${ }^{9}$ Organización Internacional para las Migraciones (OIM), Las Instituciones Nacionales de Derechos Humanos en la protección de Migrantes, Oficina Regional para América del Sur, 2013. P. 9 
derechos de ciudadanos argentinos en el exterior y derechos de los extranjeros en Argentina.

Si bien no existe un área específica sobre migración, conforme lo informado en su página web, bajo el área de Derechos Humanos creada específicamente para la protección, promoción y garantía de los derechos humanos frente a toda vulneración de los mismos, se incluye a las personas migrantes y temas de trata. (Ej. En el año 2007 realizó una investigación sobre trata y tráfico de mujeres con fines de explotación sexual en la República Argentina) y también se incluye información sobre migrantes en sus informes anuales.

Organismos No Gubernamentales (ONG)

Centro de Estudios Legales y Sociales (CELS).

Esta institución fue creada en el año de 1979, durante el periodo de la dictadura en Argentina. En un principio era un organismo que se encargaba de la búsqueda de la verdad sobre los crímenes y los desaparecidos por el terrorismo de Estado que se vivió en Argentina en los años setentas. Sin embargo, conforme fue pasando el tiempo amplió sus horizontes mirando siempre hacia los Derechos Humanos. ${ }^{10}$

Dentro de sus líneas de investigación y acción, se encuentra la migración, tema que aborda el CELS a través de publicación de investigaciones o por sus clínicas jurídicas para refugiados y migrantes, que van desde el simple asesoramiento para realizar trámites administrativos, solicitud de refugiado hasta la protección y asistencia jurídica en casos de violaciones de derechos humanos de los inmigrantes.

Fundación Comisión Católica Argentina de Migraciones (FCCAM).

A través de su labor persigue "concientizar y sensibilizar a la Iglesia, a las instituciones y a la comunidad local sobre la necesidad de entender desde una posición ética, humanista cristiana y solidaria el problema de los que deben dejar su lugar de origen con todo lo que esto implica en lo que se refiere a la violación de los Derechos Humanos; por tener que dejar la Patria, por la precarización del trabajo, por la discriminación y el aislamiento, por la disgregación de la familia y el futuro de los niños, por el tráfico infame de personas y por lo que afecta al bien

${ }^{10}$ Centro de Estudios Legales y Sociales (CELS), [en línea] Disponible: https://www.cels.org.ar/web/presentacion/ 
común de las sociedades expulsoras y receptoras el tratamiento inadecuado del fenómeno. ${ }^{11}$

\section{Fundación Ciudadanos del Mundo.}

Esta agrupación se formó con el objetivo principal de brindar una plataforma de asesoramiento para el migrante en la República Argentina, así como el desarrollo de programas de inserción social y cultural, al igual que la elaboración de proyectos de carácter jurídico, económico y social encaminados al mejoramiento de las condiciones de vida de los migrantes.

La Fundación se constituye, entonces, como un espacio donde se promueve la inclusión, la integridad y el respeto por los derechos de inmigrantes y refugiados, brindándoles asistencia y teniendo en cuenta todos los aspectos de su problemática actual.

\section{El caso de Juan Carlos De la Torre.}

En el año de 1974, el señor de origen uruguayo Juan Carlos De la Torre, ingresó a Argentina con el propósito de conseguir trabajo y poder mejorar su calidad de vida. Ante esto, la Dirección Nacional de Migraciones le concedió permiso para laborar.

De la Torre no tuvo problema alguno, hasta el 28 de Noviembre de 1996, donde tras veinticuatro años de haber vivido en la República Argentina, fue detenido por oficiales de la Policía Federal, sin exponerle alguna orden judicial que expusiera los motivos de su detención. Una vez trasladado a la Comisaría No. 12 de la Capital Federal, no se le notificaron los cargos por los cuales permaneció detenido.

Hasta este punto estamos viendo una clara violación a la garantía del debido proceso, por lo que en fecha de 3 de diciembre de 1996, abogados de víctima, presentaron un Habeas Corpus, ante el Juzgado Nacional de Instrucción $\mathrm{N}^{\circ} 40$, a favor del señor De la Torre, al enterarse que sería expulsado del país esa misma noche. En éste se planteaba la inconstitucionalidad de la Ley de Migraciones (22.349) y su decreto reglamentario (1023/94) que habilitaban la detención de un extranjero, sin orden judicial competente, y la posterior expulsión dictada por autoridad administrativa (es decir la Dirección de Migraciones), así como tampoco

\footnotetext{
${ }^{11}$ Revista Relaciones Internacionales, No. 26, Instituto de Relaciones Internacionales, 2004, [en linea] http://www.iri.edu.ar/revistas/revista_dvd/revistas/R26/ONGs\%2026/R26ONGs.pdf (recuperado el día 22 de diciembre de 2017.
} 
contemplaba la asistencia letrada necesaria ni la posibilidad de ofrecer pruebas de descargo o de impugnar judicialmente la decisión administrativa adoptada.

Ese mismo día a las 21:10 horas fue desestimado el recurso interpuesto por los abogados de De la Torre, y a las 00:00 horas del 4 de diciembre del mismo año fue expulsado del país, con la prohibición de ingresar al mismo. El Tribunal de grado, confirmo está resolución dictada por la jueza de primera instancia.

Después de una serie de recursos interpuestos por los abogados de De la Torre, este caso llego hasta la Corte Suprema de Justicia de la Nación, quien desestimó el recurso extraordinario interpuesto por los abogados, alegando que el objeto del mismo, esto es, la restricción de la libertad, se había tornado en abstracto.

Por lo que el 7 de julio de 1999, el Centro de Estudios Legales y Sociales (CELS), presentó ante Comisión Interamericana de los Derechos Humanos (CIDH) una petición de que demandaba la violación por parte de la República Argentina de los derechos a la libertad personal, a las garantías judiciales, a la protección judicial, a la no injerencia en la vida privada y a la protección de la familia, consagrados respectivamente en los artículos 7, 8, 25, 11.2 y 17 de la Convención Americana sobre Derechos Humanos.

Petición que también acogería el Centro por la Justicia y el Derecho Internacional (CEJIL), y entraría como parte peticionaria en el proceso. ${ }^{12}$

Tras una serie de actuaciones ante la CIDH, el 17 de octubre de 2003 se llevó a cabo una reunión de trabajo en el marco del $118^{\circ}$ periodo de sesiones de la CIDH en la que las partes convinieron abrir un espacio de diálogo tendiente a explorar la posibilidad de una solución amistosa del caso. Por lo que en fecha de 4 de noviembre de 2009, los peticionarios (CELS y CEJIL) y el Estado Argentino, suscribieron un acuerdo que a su tenor dice lo siguiente:

Las partes en la petición $N^{\circ} 12.306$ del registro de la Comisión Interamericana de Derechos Humanos -Juan Carlos De la Torre-: el Centro de Estudios Legales y Sociales (CELS), representado en este acto por la Dra. Andrea Pochak, y el Centro por la Justicia y el Derecho Internacional (CEJIL), representado en este acto por la Dra. Liliana Tojo, ambos en carácter de peticionarios, y el Gobierno de la República Argentina, en su carácter de Estado parte de la Convención Americana sobre Derechos Humanos, en adelante "La

\footnotetext{
${ }^{12} \mathrm{CIDH}$ Comisión Interamericana de los Derechos Humanos, Informe No. 85/11 Petición 12.306
} 
Convención", representado por el señor Subsecretario de Protección de Derechos Humanos de la Nación, Dr. Luis Hipólito Alen, la señora Directora Nacional de Asuntos Jurídicos en Materia de Derechos Humanos de la Subsecretaría de Protección de Derechos Humanos, Dra. Andrea Gualde, el señor Director de Derechos Humanos (Contencioso Internacional) de la Cancillería Argentina, Dr. Javier Salgado, el Asesor de Gabinete de la Cancillería Argentina, Dr. Jorge Cardozo, y el señor representante de la Dirección Nacional de Migraciones, Dr. Carlos Alberto Beraldi, quien suscribe este documento ad referéndum del señor Director Nacional de Migraciones, tienen el honor de informar a la llustre Comisión Interamericana de Derechos Humanos que han llegado a un acuerdo de solución amistosa de la petición, cuyo contenido se desarrolla a continuación solicitando que, en orden al consenso alcanzado, éste sea aceptado y se adopte el consecuente informe previsto por el artículo 49 de la Convención...

Debemos de tomar en cuenta que la petición interpuesta por el CELS y el CEJIL, acarreaba consigo una reforma a la ley migratoria vigente en esa época, tema que se abarcó en el acuerdo mencionado con antelación, por lo que a continuación mencionaremos algunos de los rasgos esenciales del mismo.

1) "Que conforme a reuniones anteriores, se acordó una agenda de trabajo que incluía la evaluación de diversas medidas normativas y administrativas relacionadas tanto con el marco legal en vigor en materia migratoria como así también respecto de la situación individual del señor Juan Carlos De la Torre, por lo que el día 13 de octubre de 2005, se levantó la prohibición de entrar al país al señor Juan Carlos De la Torre.

2) El proceso iniciado contribuyó de manera decisiva a la derogación de la ley de migraciones por entonces vigente, conocida como "Ley Videla", y a su sustitución por la ley 25.871, sancionada el 20 de enero de 2004; a la implementación de un mecanismo de consultas con distintas organizaciones a efectos del dictado de la reglamentación de la nueva norma; a la adopción de las medidas necesarias para la aprobación y posterior ratificación de la Convención Internacional sobre los Derechos de los Trabajadores Migrantes y de sus familias; a la suspensión de las inspecciones migratorias y sus secuelas de retenciones, detenciones $y$ expulsiones; al dictado del Decreto 836/04 que regla la normalización documentaria para todos los nativos del MERCOSUR, Chile, Bolivia y Perú; y al dictado del Decreto 1169/04 con idéntico objetivo para las personas 
oriundas de todo otro Estado. En ese sentido, el recientemente aprobado "Plan Nacional contra la Discriminación" incluye un capítulo específicamente dedicado a los migrantes y a los refugiados.

3) El Estado argentino se compromete a realizar un pormenorizado análisis de la legislación vigente en la materia (nacional y provincial) a fin de impulsar la adecuación de aquella normativa que eventualmente contenga disposiciones que efectúen discriminaciones ilegítimas con base en la condición de extranjero de la persona o en su condición migratoria a los estándares internacionales y constitucionales en la materia. En este sentido, las partes destacan la aprobación del "Plan Nacional contra la Discriminación", que incluye un capítulo específicamente dedicado a los migrantes y a los refugiados.

4) Que: este procedimiento tiene como fin "Ilegar a una solución amistosa del asunto, fundada en el respeto a los derechos humanos reconocidos en la Convención".

La aceptación de llevar a cabo este trámite, expresa la buena fe del Estado para cumplir con los propósitos y objetivos de la Convención, en virtud del principio pacta sunt servanda. También, desea reiterar que el procedimiento de solución amistosa contemplado en la Convención, permite la terminación de los casos individuales en forma no contenciosa, y ha demostrado, en casos relativos a diversos países, ofrecer un vehículo importante y efectivo de solución, que puede ser utilizado por ambas partes."13

\section{Conclusiones.}

Como logramos evidenciar, y lo cual fue propósito principal del presente trabajo, nos adentramos a los rasgos más generales de la situación migratoria en Argentina. Pasamos desde sus rasgos históricos hasta lo más actual que ha pasado en materia migratoria en aquel país.

En conclusión debemos de señalar la importancia de que las autoridades migratorias respeten los derechos humanos de los migrantes. Tal como vimos en el caso de Juan Carlos De la Torre, fue tan grave la violación generada por el

\footnotetext{
${ }^{13}$ Informe No. 85/2011 del Centro de Estudios Legales y Sociales (CELS), “Petición No. 12.306, solución amistosa, Juan Carlos De la Torre”, Argentina, 21 de julio de 2011.
} 
Estado Argentino, que dicho caso llegó a la Comisión Interamericana de Derechos Humanos.

Con lo anterior, cabe destacar la importancia que juegan las normas y los mecanismos internacionales en la resolución de un conflicto nacional.

Tanto así que se logró que ambas partes (Estado y De la Torre) llegaran a un acuerdo mutuo para solventar el problema. Además que este acuerdo trae como consecuencia la ley de migraciones que regula actualmente en Argentina.

Otro punto que hay que tomar en consideración es el rol que juegan las INDH y las ONG en los derechos del migrante, ya que como vimos en el trabajo, estas sirven como plataformas de asesoramiento e incluso de gestión para los migrantes. De igual manera con éstas, el migrante puede acudir en caso de que se le vea violado alguno de sus derechos fundamentales en un caso concreto.

Con todo lo anteriormente expuesto en el presente trabajo, no queda más que decir que debemos reflexionar y mirar el actuar de nuestras autoridades migratorias, así como de no ser ajenos a la situación migratoria que vive nuestro país, para poder evaluar si efectivamente contamos con instituciones de derecho que velen por los derechos de las personas migrantes. 


\section{Referencias bibliográficas.}

- Centro de Estudios Legales y Sociales (CELS), "El trabajo del CELS. Derechos de las personas migrantes: compartir y ampliar lecciones aprendidas en la Argentina." Mayo 2017. P.4

- CIDH Comisión Interamericana de los Derechos Humanos, Informe No. 85/11 Petición 12.306

- Informe No. 85/2011 del Centro de Estudios Legales y Sociales (CELS), "Petición No. 12.306, solución amistosa, Juan Carlos De la Torre", Argentina, 21 de julio de 2011.

- Organización Internacional para las Migraciones (OIM), Oficina Regional para América del Sur, Las Instituciones nacionales de Derechos Humanos en la protección de migrantes, 2013. P. 9

- Organización Internacional para las migraciones (OIM), "EI Impacto de las Migraciones en Argentina, Cuadernos migratorios No. 2, Abril 2012.

- Organización Internacional para las migraciones (OIM), Perfil Migratorio de Argentina 2012. P. 71.

- Sistema Continuo de Reportes sobre Migración Internacional en las Américas SICREMI, Argentina - Síntesis histórica de la migración internacional en Argentina, 2014 [en línea] Disponible: http://www.migracionoea.org/index.php/es/sicremi-es/17sicremi/publicacion-2011/paises-es/53-argentina-1-sintesis-historica-de-lamigracion-internacional-en-argentina.html

\section{Consulta web:}

- https://www.cels.org.ar/web/wp-content/uploads/2017/06/Estudio-de-casodel-CELS-sobre-derechos-de-los-migrantes.pdf 
BIOLEX Revista Jurídica del Departamento de Derecho UNISON URC

Academia de Derecho Administrativo

Tercera Época Año 10. No 18 Enero - Junio de 2018

○ https://www.cels.org.ar/web/presentacion/

○ http://servicios.infoleg.gob.ar/infoleglnternet/anexos/270000274999/271245/ norm htm (recuperado el día 15 de noviembre de 2017)

- http://www.migracionoea.org/index.php/es/sicremi-es/17sicremi/publicacion-2011/paises-es/53-argentina-1-sintesis-historica-de-lamigracion-internacional-en-argentina.html (recuperado el 20 de noviembre de 2017)

- Revista Relaciones Internacionales, No. 26 (segmento digital), Instituto de Relaciones Internacionales,2004,http://www.iri.edu.ar/revistas/revista_dvd/r evistas/R26/ONGs\%2026/R26-ONGs.pdf (recuperado el día 22 de diciembre de 2017).

\section{Leyes:}

- Constitución de la Nación Argentina. (promulgada el 22 de agosto de 1994)

- Ley 25.871, "Ley de Migraciones" de Argentina (promulgada el 20 de enero de 2004)

Fecha de recepción 02/04/2018

Fecha de aceptación 15/06/2018 